\title{
FFR 4 CABG: More than a vanity plate
}

\author{
Jack H. Boyd, MD
}

\author{
From the Department of Cardiothoracic Surgery, Stanford University School of Medicine, Stanford, Calif. \\ Disclosures: Author has nothing to disclose with regard to commercial support. \\ Received for publication Dec 15, 2015; accepted for publication Dec 16, 2015; available ahead of print Jan 22, \\ 2016. \\ Address for reprints: Jack H. Boyd, MD, Department of Cardiothoracic Surgery, Stanford University School of \\ Medicine, 300 Pasteur Dr, Falk Bldg, CV-229, Stanford, CA 94305 (E-mail: jackboyd@stanford.edu). \\ J Thorac Cardiovasc Surg 2016;151:933-4 \\ $0022-5223 / \$ 36.00$ \\ Copyright (C) 2016 by The American Association for Thoracic Surgery \\ http://dx.doi.org/10.1016/j.jtcvs.2015.12.031
}

For all surgeons involved in the treatment of coronary artery disease, the article by Casselman and colleagues ${ }^{1}$ regarding the role of fractional flow reserve (FFR) in coronary artery bypass grafting (CABG) should be a part of their wheelhouse. The rapidity in which FFR has been incorporated into routine percutaneous coronary intervention (PCI) is based on its efficacy. A thorough understanding of FFR and its effects on PCI and surgery are necessary to offer the optimal treatment available today to a patient with coronary artery disease. This article includes a clear definition of FFR and a review of the relevant randomized clinical trials demonstrating the role of FFR and the influence it has had on PCI. It, then, begins to explore the effects and implications of FFR on the surgical treatment of coronary artery disease.

Until recently revascularization strategies hinged solely on anatomic findings determined during angiography. With the advent of FFR, physiologic or functional significance of many of these lesions became available. Interventional cardiologists have used these data to improve the outcomes of PCI. Functionally nonsignificant coronary lesions can safely be deferred to medical therapy without untoward consequences. ${ }^{2}$ By refraining from stenting nonsignificant lesions, a strategy that offers no prognostic benefit, there are fewer opportunities for stent-related complications like in-stent restenosis, thrombosis, and their sequelae.

The influence of FFR on surgical revascularization is not as well studied, but there are some early trends. First, with fewer lesions being considered significant based on FFR, fewer patients will be diagnosed with left main or 3-vessel disease, common indications for $\mathrm{CABG}^{3}$ Furthermore, by incorporating a functional Synergy Between Percutaneous Coronary Intervention With Taxus and Cardiac Surgery (SYNTAX) score, many patients are downgraded from high or intermediate risk categories to low or intermediate categories treatable by both PCI and CABG.

Equally relevant to how FFR may affect the indication for CABG, is how FFR should affect the conduct of surgical revascularization. In a trial comparing FFR-guided

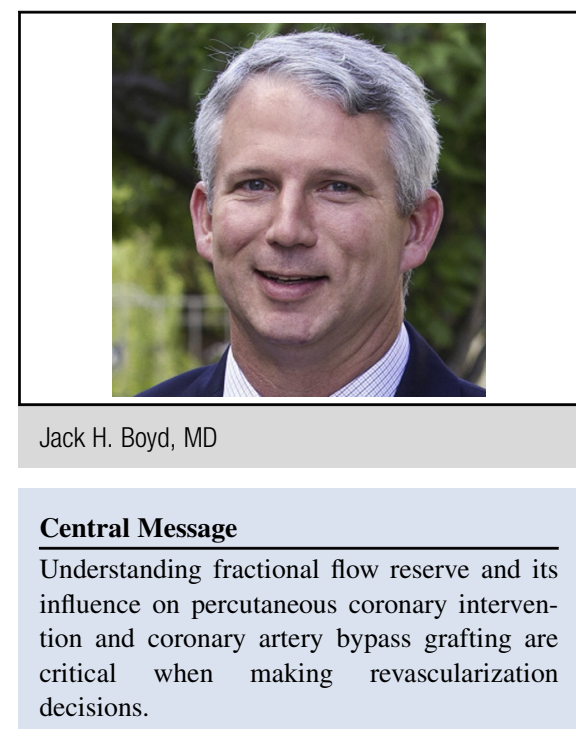

See Article page 926.

with angiography-guided $\mathrm{CABG},{ }^{4}$ fewer grafts were performed in the FFR-guided groups. Of the grafts that were performed, fewer occluded in the FFR-guided groups. Interestingly, the angiography-guided groups had no significant increase in angina or need for repeat revascularization, likely because the occluded grafts were to bypass noncritical lesions. No difference in major adverse cardiac events (eg, death, myocardial infarction, or target vessel revascularization) was seen. ${ }^{4}$

FFR is primarily applicable in stable ischemic heart disease. Even the landmark analysis of Fractional Flow Reserve-Guided Percutaneous Coronary Intervention Plus Optimal Medical Therapy Versus Optimal Medical Therapy Alone in Patients With Stable Coronary Artery Disease (FAME II) only demonstrated a survival advantage for PCI of significant lesions over medical therapy when periprocedural morbidity and mortality were excluded. ${ }^{5}$ Its role in acute coronary syndromes is less clear. There is no absolute point at which FFR becomes abnormal; rather, there is a transition with a gray zone. In most clinical trials, the tipping point has been set between 0.75 and 0.80 with higher numbers indicative of a nonsignificant stenosis and lower values indicative of significant lesions. Whether or not FFR can be used to improve CABG outcomes remains to be seen. Regardless, better classification of coronary lesions involving not only their anatomic characteristics but also their functional significance will allow for a more individualized approach to optimal revascularization. We 
look forward to the results of the Graft Patency after FFR-Guided versus Angiography-Guided CABG Trial and know that to be in the driver's seat, we need to understand the present-day potential role of FFR-guided coronary artery bypass graft surgery.

\section{References}

1. Casselman F, Van der Merwe J, Ferrara A, Barbato E. The present day potential role of fractional flow reserve-guided coronary artery bypass graft surgery. J Thorac Cardiovasc Surg. 2016;151:926-32.
2. Pijls NH, van Schaardenburgh P, Manoharan G, Boersma E, Bech JW, van't Veer M, et al. Percutaneous coronary intervention of functionally nonsignificant stenosis: 5-year follow-up or the DEFER study. J Am Coll Cardiol. 2007;49:2105-11.

3. Ahn JM, Yoon SH, Roh JH, Lee PH, Chang M, Park HW, et al. Trends in outcomes of revascularization for left main coronary disease or three-vessel disease with the routine incorporation of fractional flow reserve in real practice. Am J Cardiol. 2015; $116: 1163-71$

4. Toth G, De Bruyne B, Casselman F, De Vroey F, Pyxaras S, Di Serafino L, et al. Fractional flow reserve-guided versus angiography-guided coronary artery bypass graft surgery. Circulation. 2013;128:1405-11.

5. De Bruyne B, Pijls NHJ, Kalesan B, Barbato E, Tonino PAL, Piroth Z, et al. Fractional flow reserve-guided PCI versus medical therapy in stable coronary disease. N Engl J Med. 2012;367:991-1001. 